\section{Commentary: Chronic thromboembolic pulmonary hypertension and the misguided thrombus}

\author{
Michael Hsin, MBBChir, FRCS, CTh, ${ }^{\mathrm{a}}$ and \\ Katherine Fan, MBChB, MRCP, FRCP ${ }^{b}$
}

In this issue of the Journal, Ataam and colleagues ${ }^{1}$ report their study on patients from the French National Chronic Thromboembolic Pulmonary Hypertension (CTEPH) Registry undergoing pulmonary endarterectomy (PEA). Preoperative C-reactive protein (CRP) levels $>10 \mathrm{mg} / \mathrm{L}$ were found to be independently associated with the need for prolonged catecholamine support. The authors suggest a link between preoperative systemic inflammation and perioperative hemodynamic instability characterized by profound vasoplegia.

Of the patients who suffer from venous thromboembolism or pulmonary embolism, only a small minority $(0.1 \%-9 \%)$ develop CTEPH. ${ }^{2,3}$ It is thought that the development of CTEPH is caused by more than just thromboembolic obliteration. Normally, the thrombus is removed by a process of degradation and organization and adaptive remodeling of the vessel wall with recanalization. Leucocyte recruitment and angiogenesis play important roles in thrombus resolution. ${ }^{2}$ Epidemiologic studies have identified predisposing factors for $\mathrm{CTEPH},{ }^{4}$ such as infection (osteomyelitis) and malignancy, indwelling catheters or ventriculo-atrial shunts, splenectomy, chronic inflammatory conditions (eg, inflammatory bowel disease), non-O blood group, and genetic predisposition involving the coagulation system. ${ }^{5}$ These associations suggest infectioninduced inflammation and noninfectious inflammatory states such as malignancy may stabilize themoboemboli. ${ }^{6}$

\footnotetext{
From the ${ }^{\mathrm{a}}$ Department of Cardiothoracic Surgery, Queen Mary Hospital; and ${ }^{\mathrm{b}} \mathrm{Car}-$ diac Medical Unit, Grantham Hospital, Hong Kong.

Disclosures: Authors have nothing to disclose with regard to commercial support.

Received for publication Dec 17, 2019; revisions received Dec 17, 2019; accepted for publication Dec 18, 2019; available ahead of print Jan 7, 2020.

Address for reprints: Michael Hsin, MBBChir, FRCS, CTh, Department of Cardiothoracic Surgery, Queen Mary Hospital, Hong Kong (E-mail: mkhsin@hotmail. com).

J Thorac Cardiovasc Surg 2021;161:1543-4

$0022-5223 / \$ 36.00$

Copyright (c) 2020 by The American Association for Thoracic Surgery

https://doi.org/10.1016/j.jtcvs.2019.12.065
}

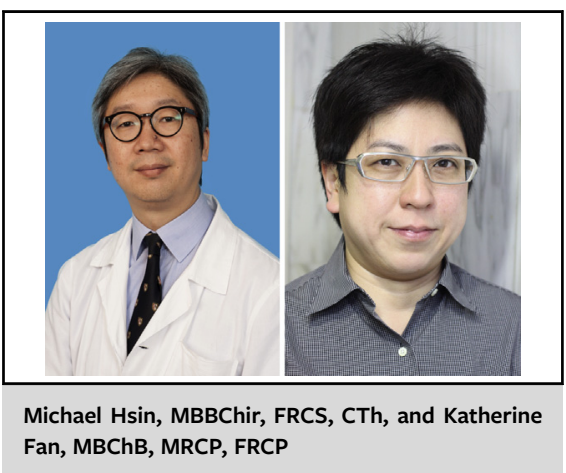

CENTRAL MESSAGE

Accumulating evidence supports the concept of inflammatory thrombosis as an important component in chronic thromboembolic pulmonary

hypertension.

Indeed, one of the pathophysiologic concepts of CTEPH is inflammatory thrombosis, where excessive inflammation may play a role in thrombus nonresolution. ${ }^{2,6}$ Other important pathophysiologic concepts include "deficient angiogenesis" and "abnormal fibrin.",

Studies based on patients with CTEPH undergoing PEA have provided support to this concept of inflammatory thrombosis. Quarck and colleagues ${ }^{7}$ examined the pulmonary vascular material collected from patients who underwent PEA. Histologic study showed that accumulation of T-lymphocytes, macrophages, and neutrophils was found mainly in atherosclerotic and thrombotic lesions.

Plasma inflammatory biomarkers levels were also found to be elevated in these patients. These included CRP, interleukin-10, monocyte chemotactic protein-1, macrophage inflammatory protein- $1 \alpha$, and matrix metalloproteinase-9. CRP and matrix metalloproteinase-9 levels were correlated with neutrophil and macrophage accumulation. $^{7}$ The presence of inflammatory cells in thrombotic and atherosclerotic, rather than neoimtimal and recanalized, lesions suggest inflammation might be an active participant in thrombus formation. ${ }^{5}$ Another study of resected PEA specimens showed that inflammatory markers, including IL-6, monocyte chemoattractant protein-1, interferon-induced protein 10 , macrophage inflammatory protein- $1 \alpha$, and chemokine ligand 5 (RANTES), were upregulated in resected PEA supernatant compared with lung tissue from healthy controls. ${ }^{8}$ 
Based on the simplified concept of "inflammatory thrombosis" triggering ongoing thrombosis, the Vienna group measured D-dimers and CRP levels in patients at the time of CTEPH diagnosis and showed that both were independent and significant predictors of outcome in CTEPH. Interestingly, after PEA, D-dimer and CRP levels decreased. These observations support important roles played by fibrin turnover and inflammation in the pathogenesis of CTEPH. ${ }^{9}$

Ataam and colleagues have taken this further and propose CRP as a biomarker for patients with CTEPH undergoing PEA. This should be further validated using different patient cohorts. Given that patients with CTEPH may be stratified according to preoperative inflammatory status, clinicians need to explore how to optimize perioperative management to achieve better outcomes in this patient population.

\section{References}

1. Ataam JA, Amsallem M, Guihaire J, Haddad F, Lamrani L, Stephan F, et al. Preoperative C-reactive protein predicts early postoperative outcomes after pulmo- nary endarterectomy in patients with chronic thromboembolic pulmonary hypertension. J Thorac Cardiovasc Surg. 2021;161:1532-42.e5.

2. Lang IM, Pesavento R, Bonderman D, Yuan JX. Risk factors and basic mechanisms of chronic thromboembolic pulmonary hypertension: a current understanding. Eur Respir J. 2013;41:462-8.

3. Pengo V, Lensing AW, Prins MH, Marchiori A, Davidson BL, Tiozzo F, et al; Thromboembolic Pulmonary Hypertension Study Group. Incidence of chronic thromboembolic pulmonary hypertension after pulmonary embolism. $N$ Engl J Med. 2004;350:2257-64.

4. Bonderman D, Wilkens H, Wakounig S, Schäfers HJ, Jansa P, Lindner J, et al. Risk factors for chronic thromboembolic pulmonary hypertension. Eur Respir J. 2009; 33:325-31.

5. Hassoun PM. Inflammation in chronic thromboembolic pulmonary hypertension: accomplice or bystander in altered angiogenesis? Eur Respir J. 2015;46:303-6.

6. Matthews DT, Hemnes AR. Current concepts in the pathogenesis of chronic thromboembolic pulmonary hypertension. Pulm Circ. 2016;6:145-54.

7. Quarck R, Wynants M, Verbeken E, Meyns B, Delcroix M. Contribution of inflammation and impaired angiogenesis to the pathobiology of chronic thromboembolic pulmonary hypertension. Eur Respir J. 2015;46:431-43.

8. Zabini D, Heinemann A, Foris V, Nagaraj C, Nierlich P, Bálint Z, et al. Comprehensive analysis of inflammatory markers in chronic thromboembolic pulmonary hypertension patients. Eur Respir J. 2014;44:951-62.

9. Skoro-Sajer N, Gerges C, Gerges M, Panzenböck A, Jakowitsch J, Kurz A, et al. Usefulness of thrombosis and inflammation biomarkers in chronic thromboembolic pulmonary hypertension-sampling plasma and surgical specimens. J Heart Lung Transplant. 2018;37:1067-74.
See Article page 1532.

\section{Commentary: Biomarkers in chronic thromboembolic pulmonary hypertension-The clot thickens}

\author{
Marc de Perrot, MD, MSc, FRCSC
}

Chronic thromboembolic pulmonary hypertension (CTEPH) is one of the main causes of pulmonary hypertension $(\mathrm{PH})$ with a prevalence ranging between 3 and 30 cases per million inhabitants. ${ }^{1}$ Pulmonary endarterectomy (PEA) is the treatment of choice. It is associated with major benefit in quality of life and can lead to long-term resolution

From the Division of Thoracic Surgery, Toronto General Hospital, Toronto, Ontario, Canada.

Disclosures: Author has nothing to disclose with regard to commercial support.

Received for publication Jan 3, 2020; revisions received Jan 3, 2020; accepted for publication Jan 9, 2020; available ahead of print Jan 31, 2020.

Address for reprints: Marc de Perrot, MD, MSc, FRCSC, Toronto CTEPH Program, Toronto General Hospital, 9N-961, 200 Elizabeth S, Toronto, Ontario M5G 2C4,

Canada (E-mail: marc.deperrot@uhn.on.ca).

J Thorac Cardiovasc Surg 2021;161:1544-5

$0022-5223 / \$ 36.00$

Copyright (c) 2020 by The American Association for Thoracic Surgery

https://doi.org/10.1016/j.jtcvs.2020.01.032
Check for updates

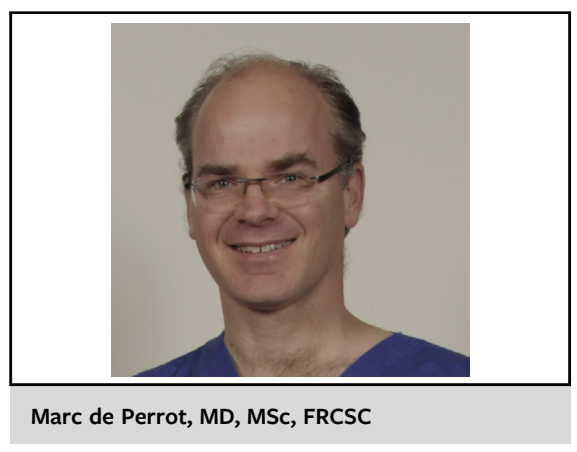

CENTRAL MESSAGE

Biomarkers are becoming

increasingly important to assess

patients with chronic thrombo-

embolic pulmonary

hypertension.

of the $\mathrm{PH}^{2,3}$ Increasing experience and refinements in surgical techniques have expanded the indications for PEA. ${ }^{4}$ Currently, patients with disease located at the level of the segmental arteries can be excellent surgical 